\begin{tabular}{|c|l|}
\hline Title & $\begin{array}{l}\text { Summer transport estimates of the Kamchatka Current derived as a variational inverse of hydrophysical and surface } \\
\text { drifter data }\end{array}$ \\
\hline Author(s) & Panteleev, G.G.; Stabeno, P.; Luchin, V.A.; Nechaev, D.A.; Ikeda, M. \\
\hline Citation & $\begin{array}{l}\text { Geophysical Research Letters, 33(9), L09609 } \\
\text { https://doi.org/10.1029/2005GL024974, 2006 }\end{array}$ \\
\hline Issue Date & $2006-05-12$ \\
\hline Doc URL & http://hdl.handle.net/2115/14407 \\
\hline Rights & An edited version of this paper was published by A GU. Copyright 2006 A merican Geophysical Union. \\
\hline Type & article \\
\hline File Information & 2006GL 024974.pdf \\
\hline
\end{tabular}

Instructions for use 
2

3

\title{
Summer transport estimates of the Kamchatka Current derived as a variational inverse of hydrophysical and surface drifter data
}

\author{
G. G. Panteleev, ${ }^{1,2}$ P. Stabeno, ${ }^{3}$ V. A. Luchin, ${ }^{4}$ D. A. Nechaev, ${ }^{5}$ and M. Ikeda ${ }^{6}$ \\ Received 23 October 2005; revised 21 December 2005; accepted 30 December 2005; published XX Month 2006.
}

[1] The quasistationary summer Bering Sea circulation is reconstructed as a variational inverse of the hydrographic and atmospheric climatologies, transport estimates through the Bering Strait, and surface drifter data. Our results indicate the splitting of the Kamchatka Current in the vicinity of the Shirshov Ridge. This branching is in agreement with independent ARGO drifter observations. It was also found, that transport of the Kamchatka Current gradually increases downstream from $14 \mathrm{~Sv}$ in the Olyutorsky Gulf to $24 \mathrm{~Sv}$ in the Kamchatka Strait, which is twice higher than previous estimates. Citation: Panteleev, G. G., P. Stabeno, V. A. Luchin, D. A. Nechaev, and M. Ikeda (2006), Summer transport estimates of the Kamchatka Current derived as a variational inverse of hydrophysical and surface drifter data, Geophys. Res. Lett., 33, LXXXXX, doi:10.1029/ 2005 GL024974.

\section{Introduction}

[2] The circulation and distributions of the hydrophysical properties in the Bering Sea (BS) determine the heat and fresh water exchange between the North Pacific and Arctic Oceans. The circulation in the BS basin is driven by the atmospheric forcing and the inflow/outflow transports through four primary passes: Kamchatka Strait, Near Strait, Amchitka Pass and Amukta Pass [Stabeno et al., 2005]. The currents in the Bering Strait are relatively well monitored by velocity moorings [Woodgate et al., 2005], while the water transports through the straits and passages of the Aleutian Arc have been mainly explored through the estimates of the baroclinic currents by dynamical method [Verhunov and Tkachenko, 1992; Stabeno and Reed, 1992]. The transport through the Kamchatka Strait is the major outflow from the $\mathrm{BS}$. This region is one of the least studied in the BS because of known difficulties in accessing the Russian historical data. The estimates of the Kamchatka Current (KC) transport are based mainly on the hydrophysical data and range from $5 \mathrm{~Sv}$ [Verkhunov and Tkachenko, 1992] to $15 \mathrm{~Sv}$ [Ohtani, 1970] in dynamical calculations and 8-13 Sv in numerical modelling studies [Overland et al., 1994]. Un-

\footnotetext{
${ }^{1}$ International Arctic Research Center, University of Alaska Fairbanks, Fairbanks, Alaska, USA.

${ }^{2}$ Also at Shirshov Institute of Oceanology, Russian Academy of Sciences, Moscow, Russia.

${ }^{3}$ Pacific Marine Environmental Laboratory, Seattle, Washington, USA.

${ }^{4}$ Il'ichev Pacific Oceanological Institute, Far Eastern Branch, Russian Academy of Science, Vladivostok, Russia.

${ }^{5}$ Department of Marine Science, University of Southern Mississippi, Stennis Space Center, Mississippi, USA.

${ }^{6}$ Graduate School of Environmental Earth Science, Hokkaido University, Sapporo, Japan.
}

Copyright 2006 by the American Geophysical Union. 0094-8276/06/2005GL024974\$05.00 fortunately, the results of both these methods depend on a 46 number unknown parameters, such as the level of no motion 47 or poorly known boundary conditions and tidal rectification 48 through many of the passes that are often not resolved in 49 models [Stabeno et al., 2005].

50

[3] The goal of this study is to quantify the summer 51 circulation in the central $\mathrm{BS}$ and to derive reliable estimates 52 of the KC transport by combining the information from all 53 ayailable data sources with the dynamical constraints of the 54 primitive equation numerical model. We solve this problem 55 through the variational assimilation of temperature/salinity, 56 drifter and meteorological data into the ocean general 57 circulation model [Nechaev et al., 2005; Panteleev et al., 58 2006]. The summer period was chosen as the period with 59 the best data coverage.

\section{Data}

[4] In the presented research we utilize data sets as 62 follows.

63

2.1. 41,911 Temperature/Salinity Profiles Collected in 64 the Chukcha and Bering Seas (Between $55^{\circ} \mathrm{N}$ and $69^{\circ} \mathrm{N}$ ) 65 During the Summer (July-September)

[5] This database includes bottle data, mechanical bathy- 67 thermograph data, high resolution CTD, expendable bathy- 68 thermograph and PALACE ARGO drifter data. The data 69 were collected by US, Japanese and Russian organizations 70 during the period 1932-2004. The major part of the data 71 was obtained from historical databases in RIHMI-WDC 72 (http://www.meteo.ru/nodc/), JODC (http://jdoss1.jodc. 73 go.jp), University of Alaska (http://www.ims.uaf.edu), data- 74 bases of Levitus [Levitus et al., 2001], and Argo Global 75 Data Assembly Centre (http://www.coriolis.eu.org//cdc/ 76 argo.htm). Some of Russian data are classified and not 77 available to the public at present. Figure 1 shows the spatial 78 distribution of salinity profiles. These climatological data 79 and estimates of their standard deviation (STD) were used 80 in data assimilation. Temperature/salinity STD varied within 81 the ranges $0.5^{\circ} \mathrm{C}-1.5^{\circ} \mathrm{C}$ and $0.1-2.0$ near the surface and 82 decreased down to $0.1^{\circ} \mathrm{C}$ and 0.03 respectively on deeper 83 levels $(1000 \mathrm{~m})$.

2.2. 500 Satellite-Tracked Drifters Trajectories From 85 Fisheries Oceanography Coordinated Investigations 86 (NOAA) Database (http://www.pmel.noaa.gov/foci/ 87 FOCI_data.html)

[6] All surface drifters utilized in this paper had drougues 89 at approximately $40 \mathrm{~m}$ [e.g., Stabeno and Reed, 1994]. The 90 preliminary analysis of these data included: (i) extraction of 91 summer drifter trajectories; (ii) temporal low-pass filtering 92 with a 7 days cutoff period; (iii) spatial interpolation and 93 smoothing of the filtered drifter velocity components onto 94 


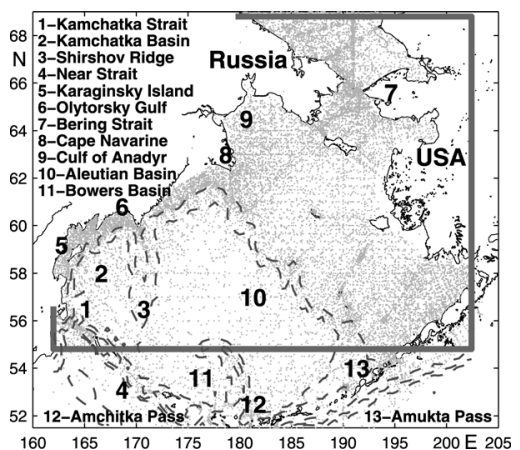

Figure 1. Spatial distribution of the summer historical salinity data in the Bering Sea. The model domain is shown by thick line. Dashed lines mark the $1000 \mathrm{~m}$ and $3000 \mathrm{~m}$ isobaths.

the model grid with correlation radius of $40 \mathrm{~km}$; (iv) estimation of the error variance of gridded velocity components. We assimilated only "reliable" velocities obtained from the averaging of at least three different surface drifters (Figure 2).

\subsection{Estimates of the Total Summer Transports Through the Bering Strait}

[7] Transport estimates of $1.1 \pm 0.2 \mathrm{~Sv}$ were taken from [Woodgate et al., 2005].

\subsection{NCEP/NCAR Wind Stress and Surface} Heat/Salt Flux Climatology

[8] These climatologies (http://www.cdc.noaa.gov/cdc/ data.ncep.reanalysis.derived.html) were found to be extremely smooth. To allow for the adjustment of the spatial details in the model forcing we used wind stress and heat/ salt flux data with relatively high error variance equal to $40 \%$ of their spatial and temporal variability in the BS. Significant errors in the NCEP/NCAR forcing were also noticed by Ladd and Bond [2002].

\section{Data Assimilation Technique}

[9] To find the optimal solution of the model we perform strong constraints minimization of the cost function measuring the distance between the model solution and data on the space of the control variables [Le Dimet and Talagrand, 1986]. Control variables include the initial conditions, the model field values required to specify the open boundary conditions, and the surface fluxes of momentum, heat and salt [Nechaev et al., 2005].

[10] The primitive equation model utilized in this study was successfully used for the reconstruction of the climatological circulation in the Barents Sea [Panteleev et al., 2006] and for the nowcast of the circulation in the Tsushima Strait [Nechaev et al., 2005]. The model is a modification of the C-grid, $z$-coordinate OGCM designed by Madec et al. [1999]. The model is implicit both for barotropic and baroclinic modes permitting model runs with relatively large time steps [Nechaev et al., 2005]. The model is configured in the domain shown in Figure 1 and is used in "climatological", "quasistationary" [Tziperman and Thacker, 1989] non-eddy-resolving mode on a relatively coarse regular z-coordinate grid. The meridional resolution 136 of the grid is $0.2^{\circ}$, zonal resolution $-0.4^{\circ}$, and the time step 137 is 4 hours. Vertically the grid has 34 levels with unequal 138 spacing ranging from $5 \mathrm{~m}$ at the surface to $500 \mathrm{~m}$ in the 139 deeper levels. The smaller passes in the Aleutian Arc are not 140 resolved, but the primary ones are.

[11] Statistical interpretation of the variational data as- 142 similation technique [Thacker, 1989] considers the cost 143 function as an argument of the Gaussian probability distri- 144 bution with the cost function weights being the inverse 145 covariances of the corresponding data errors. In the present 146 study we use the cost function $\mathcal{J}$ containing "data", 147 "smoothness" and "stationarity" terms:

$$
\begin{gathered}
\mathcal{J}=\mathcal{J}_{\text {data }}+\mathcal{J}_{\text {smoth }}+\mathcal{J}_{\text {stat }}, \quad \text { where } \\
\mathcal{J}_{\text {data }}=W_{y}^{-1}\left(y-y^{*}\right)^{2}+W_{Y}^{-1}\left(L y-Y^{*}\right)^{2}, \\
\mathcal{J}_{\text {smoth }}=\int_{\Omega, t} W_{y, s}^{-1}\left(\nabla^{2} y\right)^{2} d \Omega d t, \\
\mathcal{J}_{\text {stât }}=\int_{\Omega, t} W_{y, t_{1}}^{-1}(\partial y / \partial t)^{2}+W_{y, t_{2}}^{-1}\left(\partial^{2} y / \partial t^{2}\right)^{2} d \Omega d t .
\end{gathered}
$$

[12] Here $\Omega$ is the model domain; $y$ stands for the vector 151 of the model solution, and $y^{*}$ - for the corresponding 152 gridded data; $Y^{*}$ denotes the data, which are not direct 153 measurement of the model state vector and require some 154

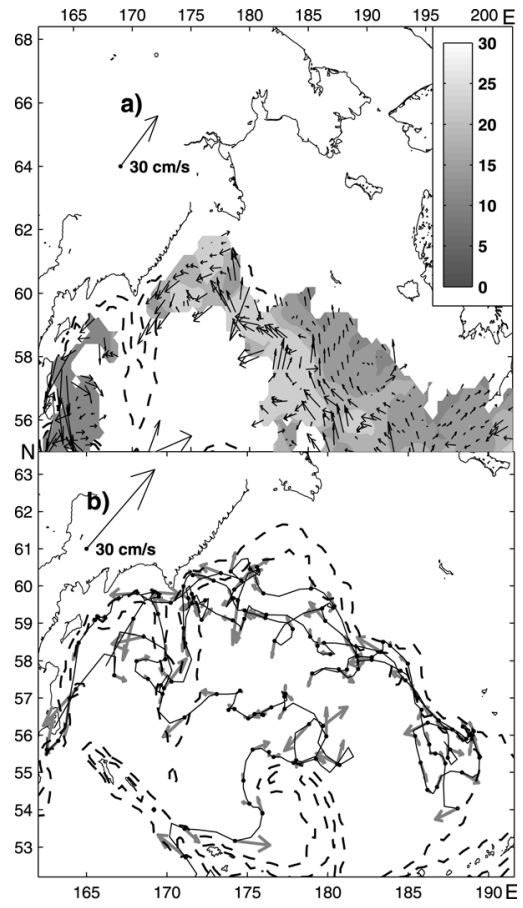

Figure 2. (a) Averaged summer velocities at $40 \mathrm{~m}$ derived from drifter data. The shaded areas show the spatial distribution of zonal velocity STD, which ranges from 5 $\mathrm{cm} / \mathrm{sec}$ to $20 \mathrm{~cm} / \mathrm{sec}$. (b) The trajectories and 2-day mean velocities of the four ARGO drifters (http://www.usgodae.org) parked at $1000 \mathrm{~m}$ during 2002-2004. Circles and asterisks designate the initial and final location of the drifter. Dashed lines denote $1000 \mathrm{~m}$ and $3000 \mathrm{~m}$ isobath. 


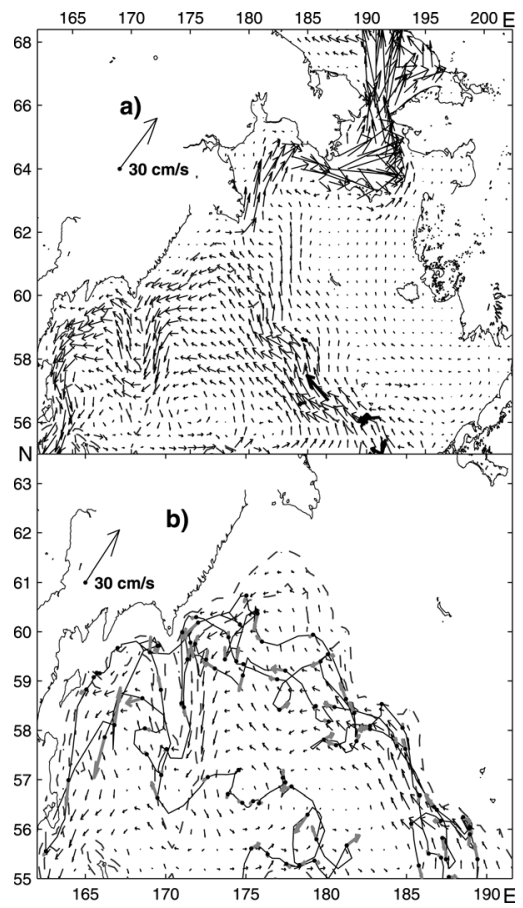

Figure 3. The optimized velocities at (a) $17 \mathrm{~m}$ and (b) $1000 \mathrm{~m}$ obtained in the experiment A. Thick arrows denote the mean velocities observed at several moorings (Figure 3a) and ARGO velocities at $1000 \mathrm{~m}$ (Figure 3b). operator $L$ acting on the model solution $y$ to compute model-data counterparts (e.g., $L$ can calculate the transports through the open boundaries). The diagonal matrices $W_{y}$, $W_{Y}, W_{y, s}$ are the variances of the corresponding data and smoothness terms (see Data section).

[13] In the course of $\mathcal{J}$ minimization, the term $\mathcal{J}_{\text {data }}$ forces the model solution to be close to the data, the term $\mathcal{J}_{\text {smoth }}$ penalizes grid-scale noise. The "stationarity" cost function term $\mathcal{J}_{\text {stat }}$ allows us to obtain a quasi-steady state model solution [Tziperman and Thacker, 1989] and to find the estimates of the summer climatological state. The weights $W_{y, t_{1}}$ and $W_{y, t_{2}}$ define "degree" of stationarity of model solution. The climatological temperature/salinity distributions and the corresponding geostrophic velocities were used to set up boundary and initial conditions for the first guess solution of the model.

\section{Results}

[14] The reconstruction of the climatological summer circulation was done using quasistationary variational data assimilation approach proposed by Tziperman and Thacker [1989]. We carried out two numerical experiments:

[15] Experiment A: we assimilated all the observations outlined above, i.e., temperature and salinity climatologies, surface drifter data, the Bering Strait transport, and meteorological data.

[16] Experiment B: we did not assimilate the surface drifter data, but instead, we added to the cost function the transport estimate of $12 \pm 4 \mathrm{~Sv}$ through the Kamchatka Strait. This outflow estimate is derived from a number of publications implementing the dynamical method calcula- tions [e.g., Stabeno and Reed, 1992; Verhunov and Tka- 185 chenko, 1994].

\subsection{Experiment A}

187

[17] The optimized velocity fields obtained in experiment 188 A are shown in Figure 3. General circulation pattern agrees 189 with conventional scheme of the BS circulation, which 190 includes week currents on the eastern shelf, the Bering 191 Slope current (BSC), the intensive KC along the Eurasian 192 continent, the intensive Navarine Current in the Gulf of 193 Anadir and the strong northward flow in the Bering Strait. 194 The KC originates as a continuation of the BSC at approx- 195 imately $175^{\circ}$ and then flows clockwise around the Shirshov 196 Ridge. The obtained circulation reveals strong topographic 197 steering of the KC. According to our results, in the vicinity 198 of the point $58^{\circ} \mathrm{N}, 170^{\circ} \mathrm{E}$ the $\mathrm{KC}$ splits into two branches. 199 One of these branches (we will call it "coastal branch") 200 follows northward along the $1000 \mathrm{~m}$ isobath, while, the 201 other branch ("off-shore branch") flows westward across 202 the Kamchatka Basin and joins the coastal branch of the KC 203

near the Karaginsky Island. This is similar to the flow 204 pattern by Stabeno and Reed [1994]. These branches join 205 northeast of the Karaginsky Island resulting in the gradual 206 increase of the KC transport from approximately $14 \mathrm{~Sv}$ in 207 the Olyutorski Gulf to $24 \mathrm{~Sv}$ in the Kamchatka Strait. The 208 obtained estimate of the $\mathrm{KC}$ transport is almost 1.5-2 times 209 hígher than the "traditional" estimates derived by dynam- 210 ical method.

[18] The mean relative error between modeled surface 212 velocities (Figure 3a) and drifter velocities (Figure 2a) is 213 0.71 . This relatively high error can be explained by the high 214 STD of drifter velocities, which reaches $20 \mathrm{~cm} / \mathrm{s}$ in the BSC 215 (Figure 2a). Despite the high error, the absolute amplitude 216 of the surface velocities in Bering Slope and Kamchatka 217 Currents (Figure 3a) are close to the amplitude of drifter 218 velocities shown in Figure 2a. A limited amount of avail- 219 able mooring velocities (Figure 3a, thick arrows) reveals 220 very good agreement with optimized velocities. Unfortu- 221 nately, most of these data are located in the eastern part of 222 the $\mathrm{BS}$ and cannot confirm the reliability of the $\mathrm{KC} 223$ reconstruction. Because of that, we compare our results 224 with the trajectories of four ARGO drifters (www.usgodae. 225 org), which were launched at $1000 \mathrm{~m}$ depth.

[19] Three of these drifters were released in the south- 227 eastern part of the BS and were carried by the BSC up to 228 $58^{\circ}-59^{\circ} \mathrm{N}$ where they deflected from the continental slope 229 and drifted across the Aleutian Basin to the Shirshov Ridge, 230 where they joined KC. One of these drifters entered the KC 231 and sailed clockwise around the Shirshov Ridge up to $60^{\circ} \mathrm{N} ; 232$ that is, the trajectory of this drifter follows the "coastal" 233 branch of the KC discussed above (Figures 3a and 3b). The 234 fourth drifter entered the BS through the Near Strait 235 (Figure 2b). The drifter crossed the Bowers and Aleutian 236 Basins and joined the $\mathrm{KC}$ near the southern end of the 237 Shirshov Ridge (Figure 3b) and drifted clockwise around 238 the ridge. This drifter deflected westward at $58^{\circ} \mathrm{N}, 170^{\circ} \mathrm{E} 239$ following the "off-shore" branch of the $\mathrm{KC}$ obtained in 240 our results. The splitting of the $\mathrm{KC}$ at this point is 241 probably caused by sharp bottom topography changes in 242 the Shirshov Ridge region. Analysis of bottom relief 243 (Figure 1) allows us to speculate, that off-shore branch 244 initially follows the $3000 \mathrm{~m}$ isobath and then deflects 245 


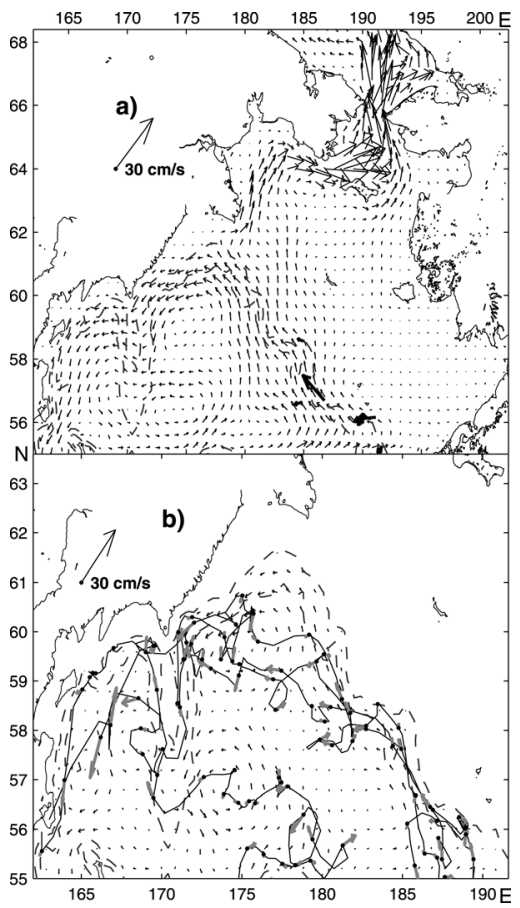

Figure 4. The optimized velocities at (a) $17 \mathrm{~m}$ and (b) $1000 \mathrm{~m}$ obtained in the experiment B. Thick arrows denote the mean velocities observed at several moorings (Figure 4a) and ARGO velocities at $1000 \mathrm{~m}$ (Figure 4b). westward near $58^{\circ} \mathrm{N}, 170^{\circ} \mathrm{E}$, while the trajectory of the coastal branch of the $\mathrm{KC}$ coincide with the $1000 \mathrm{~m}$ isobath.

[20] The 2-day mean velocities of the ARGO drifters are shown in Figure $2 \mathrm{~b}$. The averaged speed of these four drifters was approximately $4.5 \mathrm{~cm} / \mathrm{sec}$. This value is close to the mean $3.5 \mathrm{~cm} / \mathrm{sec}$ speed of the modeled currents at $1000 \mathrm{~m}$ (Figure 3b). That seems to be a good agreement with observations, because Lagrangian velocity estimates tend to be larger than Eulerian.

\subsection{Experiment B}

[21] Velocity field obtained in experiment B are shown in Figure 4. The solution without drifter data assimilation retains most of the features of the BS circulation [Stabeno and Reed, 1994] and visually the circulation pattern is similar to the circulation in Figure 3. Meanwhile, the detailed analysis reveals both qualitative and quantitative differences.

[22] For example, the BSC in the experiment $\mathrm{B}$ does not deflect westward in the vicinity of $59^{\circ} \mathrm{N}$ and continues to follow the slope up to $62^{\circ} \mathrm{N}$. That contradicts to the trajectories of all ARGO drifters in this region (Figures $2 \mathrm{~b}$ and $4 \mathrm{~b}$ ). Both surface and deep velocities in Figure 4 do not reveal "branching" of the $\mathrm{KC}$ on the western slope of the Shirshov Ridge $\left(58^{\circ} \mathrm{N}, 170^{\circ} \mathrm{E}\right)$, which is supported by ARGO drifters trajectories.

[23] The quantitative analysis of the velocity fields reveals even stronger difference between velocities in Figure 4 and observations. On the level of $1000 \mathrm{~m}$, the averaged speed in the experiment B (Figure 4b) is approximately $1.5 \mathrm{~cm} / \mathrm{s}$, which is more than two times smaller than the velocities in the experiment $\mathrm{A}(3.3 \mathrm{~cm} / \mathrm{s})$ and three times smaller than the observations of ARGO floats $(4.5 \mathrm{~cm} / \mathrm{s}), 277$ Similar differences can be observed in the surface layer: the 278 surface velocities in the experiment B in the vicinity of 279 Kamchatka Strait is only about $5 \mathrm{~cm} / \mathrm{sec}$, while the drifters 280 give the averaged estimate of $20-30 \mathrm{~cm} / \mathrm{s}$. Overall we can 281 state, that the velocity field obtained in the experiment B 282 only approximately agrees with the available velocity 283 observations.

\section{Conclusions}

[24] The performed numerical experiments and compar- 287 ison with surface and ARGO drifters reveal the splitting of 288 the $\mathrm{BSC}$ in the vicinity of $58^{\circ} \mathrm{N} 180^{\circ} \mathrm{E}$ and $\mathrm{KC}$ on the 289 western slope of the Shirshov Ridge and indicate that 290 traditional transport estimate of $12 \mathrm{~Sv}$ through the Kam- 291 chatka Strait is not a realistic climatological estimate. The 292 most probable climatological summer state (experiment A) 293 derived from the assimilation of all available data 294 [Thacker, 1989] shows that the transport of the KC 295 increases gradually from $14 \mathrm{~Sv}$ in the Olyutorsky Gulf to 296 $24 \mathrm{~Sv}$ in the Kamchatka Strait. Our KC transport estimate 297 is in a good agreement with the $20 \mathrm{~Sv}$ summer KC 298 transport obtained by combining the section hydrophysical 299 data and surface floats data by Hughes et al. [1974]. Also, 300 higher than traditional transport estimates has been 301 obtained recently by Stabeno et al. [2005]. This paper 302 provides the analysis of the direct velocity measurements 303 and derives the inflow estimate into the Bering Sea of $4 \mathrm{~Sv} 304$ through the Amutka Pass, which is five times higher than 305 the previous estimates.

306

[25] We speculate that the difference between the tradi- 307 tional transport estimates and the results of the present study 308 can be explained by some underestimation of the barotropic 309 velocity component in the Bering Sea in the traditional 310 transport estimates. To support this speculation we calcu- 311 lated baroclinic transport through the Kamchatka Strait by 312 dynamical method with zero bottom velocities from hydro- 313 graphic data utilized in the paper. Our estimate of the 314 baroclinic transport of approximately $10 \mathrm{~Sv}$ appeared to 315 be very close to the traditional transport estimates cited in 316 the literature [Ohtani, 1970; Verhunov and Tkachenko, 317 1994].

[26] Due to the model limitations the study region does 319 not extend south of $55^{\circ} \mathrm{N}$. In the future we plan to apply 320 similar technique for the reconstruction of BS circulation 321 within it's natural boundaries (Aleutian Arc and Bering 322 Strait) and to provide comprehensive analysis of the tem- 323 perature/salinity distributions and posterior error analysis. 324

[27] Acknowledgments. This study was funded by the FRSGC, 325 through JAMSTEC, Japan, and sponsorship of IARC. The study was 326 supported by the ONR Grant N00014-00-1-0201, NSF Grant OCE-01- 327 18200 and RFFI Grant 06-05-96065. This is also contribution 2873 to 328 PMEL.

\section{References}

Hughes, F. W., L. K. Coachman, and K. Aahaard (1974). Circulation, 331 transport and water exchange in the western Bering Sea, in Oceanogra- 332 phy of the Bering Sea With Emphasis on Renewable Resources, edited by 333 D. W. Hood and E. J. Kelley, pp. 59-98, Inst. of Mar. Sci., Univ. of 334 Alaska Fairbanks, Fairbanks.

Ladd, C., and N. Bond (2002), Evaluation of the NCEP/NCAR reanalysis 336 in the NE Pacific and at the Bering Sea, J. Geophys. Res., 107(C10), 337 3158, doi:10.1029/2001JC001157. 
Le Dimet, F. X., and O. Talagrand (1986), Variational algorithms for analysis and assimilation of meteorological observations: Theoretical aspects, Tellus, Ser. A, 38, 97-100.

Levitus, S., et al. (2001), World Ocean Database [CD-ROM], Natl. Oceanogr. Data Cent., Silver Spring, Md.

Madec, G., P. Delecluse, M. Imbard, and C. Levy (1999), OPA8.1 Ocean General Circulation Model Reference Manual, Notes Pole Model., vol. 11, 91 pp., Inst. Pierre-Simon Laplace, Paris.

Nechaev, D., G. Panteleev, and M. Yaremchuk (2005), Reconstruction of the circulation in the limited region with open boundaries: Circulation in the Tsushima Strait, Okeanologiya, 45, 805-828.

Ohtani, K. (1970), Relative transport in the Alaskan Stream in winter, J. Oceanogr. Soc. Jpn., 26, 271-282.

Overland, J. E., M. C. Spillane, H. E. Hurlburt, and A. J. Wallcraft (1994), A numerical study of the circulation of the Bering Sea basin and exchange with the North Pacific Ocean, J. Phys. Oceanogr., 93, 15,61915,637 .

Panteleev, G., D. Nechaev, and M. Ikeda (2006), Reconstruction of summer Barents Sea circulation from climatological data, Atmosphere Ocean, in press.

Stabeno, P. J., and R. K. Reed (1992), A major circulation anomaly in the western Bering Sea, Geophys. Res. Lett., 19, 1671-1674.

Stabeno, P. J., and R. K. Reed (1994), Circulation in the Bering Sea basin observed by satellite-tracked drifters: 1986-1993, J. Phys. Oceanogr. $24,848-854$
Stabeno, P. J., D. G. Kachel, and M. E. Sullivan (2005), Observation from 364 moorings in the Aleutian Passes: Temperature, salinity and transport, 365 Fish. Oceanogr., 14, suppl. 1, 39-54.

Thacker, W. C. (1989), The role of the Hessian matrix in fitting models to 367 measurements, J. Geophys. Res., 94, 6177-6196. 368

Tziperman, E., and W. C. Thacker (1989), An optimal-control/adjoint equa- 369 tion approach to studying the oceanic general circulation, J. Phys. Ocea- 370 nogr. $19,1471-1485$.

Verhunov, A. V., and Y. Y. Tkachenko (1994), Recent observations of 372 variability in the western Bering Sea current system, J. Geophys. Res., 373 97, 14,369-14,376.

Woodgate, R. A., K. Aagaard, and T. J. Weingartner (2005), Monthly 375 temperature, salinity, and transport variability of the Bering Strait through 376 flow, Geophys. Res. Lett., 32, L04601, doi:10.1029/2004GL021880. 377

M. Ikeda, Graduate School of Environmental Earth Science, Hokkaido 379 University, Sapporo 060-0810, Japan. 380

V. A. Luchin, Il'ichev Pacific Oceanological Institute, Far Eastern 381 Branch, Russian Academy of Science, Vladivostok 690041, Russia. 382

D. A. Nechaev, Department of Marine Science, University of Southern 383 Mississippi, Stennis Space Center, MS 39529-9904, USA. 384

G. G. Panteleev, International Arctic Research Center, University of 385 Alaska Fairbanks, Fairbanks, AK 99775-7335, USA. (gleb@iarc.uaf.edu) 386 P. Stabeno, Pacific Marine Environmental Laboratory, Seattle, WA 387 98115-6349, USA. 